\title{
The Impact of Process Variables on the Removal of PBDEs and NPEOs During Simulated Activated Sludge Treatment
}

\author{
Katherine Langford ${ }^{1}$, Mark Scrimshaw ${ }^{2}$ and John Lester ${ }^{3}$
}

\begin{abstract}
Sewage effluent is known to be a major source of endocrine disrupting compounds entering the aquatic environment. More efficient wastewater treatment could reduce the environmental load but, in order to achieve this factors determining compound behaviour must be understood. The knowledge of compound fate is becoming increasingly important for risk assessments and to allow modifications to wastewater treatment works to facilitate treatment of these compounds. This work illustrates that the removal of some endocrine disrupting compounds from sewage treatment works effluent is dependent on parameters such as sludge age, influent concentrations, concentrations of co-metabolites and hydraulic retention time as well as physico-chemical compound properties. From this research it is apparent that the principle environmental risk of plybrominated diphenyl ether contamination after wastewater treatment is via sludge disposal routes. Treatment of wastewater containing nonylphenol polyethoxylate surfactants poses environmental risks via two routes, some nonylphenolic compounds may pass through into receiving waters and degradation products such as nonylphenol and short chain ethoxylate compounds will enter the environment via sludge disposal.
\end{abstract}

\footnotetext{
${ }^{1}$ NIVA, Norwegian Institute for Water Research, Gaustadaleen 21, NO-0349, Oslo, Norway

${ }^{2}$ Institute for the Environment, Brunel University, Uxbridge, UK

${ }^{3}$ School of Water Sciences, Cranfield University, Cranfield, Bedfordshire, UK
} 


\section{Introduction}

It is well documented that chemicals discharged into the environment can, through their effects on the endocrine system, cause disruption to normal physiological functions of exposed organisms. The fate and affects of these chemicals in the environment are of increasing concern with respect to the affects on the environment, human health and reproduction. Endocrine disruption has become a topical issue over the last decade mainly due to concerns over the feminisation of fish. The increasing frequency of reports in the press and other media as well as in scientific literature are raising public awareness and as a result the effects of chemicals on the endocrine function is becoming a more important issue.

One of the major point sources of organic compounds, including endocrine disrupting chemicals (EDCs), to the environment are discharges from sewage treatment works (STW). Effluent containing water soluble compounds is discharged to the aquatic environment and sludge containing less soluble compounds is recycled during land application, disposed of to landfill or incineration. Whatever disposal route a compound follows its potential impact on the environment is of concern, therefore an understanding of its fate during wastewater treatment processes is important in assessing its environmental impact.

Due to detection of nonylphenol polyethoxylates (NPEOs) in influent and effluent, NPEO removal pathways are of increasing concern particularly as their breakdown can result in the formation of short chain NPEO compounds and nonylphenol (NP) which have demonstrated enhanced estrogenicity and increased toxicity (Servos, 1999). Polybrominated diphenyl ether (PBDE) flame retardants are also of considerable interest due their endocrine disrupting properties and their bioaccumulation potential. In this study Husmann apparatus have been used for activated sludge simulation to assess the fate and behaviour of NPEOs and PBDEs during wastewater treatment. Husmann apparatus have been used in numerous degradation studies ().

It is possible to control the fate of some compounds by controlling such factors as sludge age $\left(\varnothing_{\mathrm{c}}\right)$, hydraulic retention time (HRT) and dilution but in doing so relative cost benefits must be considered. Alleviating one environmental burden may simply 
move it elsewhere, for example the environmental impact of extending a STW plant for greater treatment efficiency may be greater than the release of EDCs into the aquatic environment.

\section{Materials and methods}

\section{Husmann operation}

The Husmann apparatus used in these experiments is represented schematically in Figure 1. A 3 I aerator and a 2 I settling tank were constructed from borosilicate glass. Air was diffused through a borosilicate glass sinter (Sinter Glass No. 2) in the bottom of the aeration chamber to aerate and also to mix the MLSS. The air was supplied at a rate of $31 \mathrm{~min}^{-1}$ to provide a dissolved oxygen concentration of 2-2.5 $\mathrm{mg} \mathrm{l}^{-1}$. Sludge was continuously recycled from settler to the aerator at $975 \mathrm{ml} \mathrm{h}^{-1}$ using a peristaltic pump (Waton-Marlow Bredel Pumps, UK). Depending on the required sludge age or MLSS concentration, sludge was automatically wasted at 24 hour intervals. Effluent was decanted off continuously from the settling chamber. The aerator was fitted with a PTFE scraping blade to limit the occurrence of bacterial growth on the sides of the glassware and a PTFE agitator was mounted in the settling tank to prevent blockages and to aid recycling by improving settling. Both of these were rotated mechanically at $10 \mathrm{rpm}$. A concentrated solution of synthetic sewage medium was prepared in a $10 \mathrm{I}$ aspirator and autoclaved for 20 minutes at $121^{\circ} \mathrm{C}$ (Table 1). The medium was fed into the aeration vessel at a rate of $29 \mathrm{ml} \mathrm{h}^{-1}$ and diluted with tap water fed at a rate of $975 \mathrm{ml} \mathrm{h}^{-1}$. The resulting influent properties are displayed in table 2 alongside the effluent properties. There were no deliberate bacterial inoculations; growth resulted from inoculation from the atmosphere. Marked shifts in bacterial communities have been observed particularly where sludge has been exposed to very different conditions such as removal from STW into laboratory based studies. Shifts in bacterial populations are less when changes in conditions are reduced, therefore allowing the Husmann apparatus to be inoculated from the atmosphere increased population stability as conditions remained constant and bacteria present are already adapted to the environment. 
For spiking the Husmann apparatus an additional 10 I aspirator was prepared containing the commercial surfactant formulation Igepal CO520 (Sigma-Aldrich, UK) or the OcBDE commercial flame retardant formulation DE-79 (Donated by CEFAS, UK).

The Husmann apparatus was operated for a 49 day test period with a constant 5 day $\varnothing_{\mathrm{c}}$ at $19 \pm 0.5^{\circ} \mathrm{C}$ with an influent Igepal C0520 concentration of $0.1 \mathrm{mg} \mathrm{l}^{-1}$. This enabled the pathway of NPEO degradation to be observed. After a period of 20 days the influent concentration was doubled to $0.2 \mathrm{mg} \mathrm{l}^{-1}$ to observe any effects of shock loadings. Another system was operated under the same conditions for PBDE inoculation at $0.02 \mathrm{mg} \mathrm{l}^{-1}$.

The Husmann apparatus was then operated at 2 different $\varnothing_{\mathrm{c}}$ ( 3 and 7 days) to determine the impact of different bacterial numbers on NPEO degradation. Both Husmann apparatus were inoculated with the same concentration of Igepal CO520 $\left(0.2 \mathrm{mg} \mathrm{l}^{-1}\right)$ at the same rate for comparable results. To observe competition effects, an additional Husmann apparatus was inoculated simultaneously with PBDEs (0.02 $\left.\mathrm{mg} \mathrm{l}^{-1}\right)$ and NPEOs $\left(0.2 \mathrm{mg} \mathrm{l}^{-1}\right)$.

\section{Methods of analysis}

Sample aliquots were taken from the aeration chamber, settling chamber, influent and effluent. Methods of analysis have been described in detail elsewhere (Langford et al., 2004). Briefly, aliquots taken for the analysis of PBDEs were initially filtered $(0.45 \mu \mathrm{m} \mathrm{GF/C})$ under vacuum to separate the solid and aqueous phases. Filter papers and collected solids were extracted by soxhlet extraction for 4 hours with $100 \mathrm{ml}$ 50/50 hexane/acetone. Solvent extracts were cleaned up over deactivated neutral alumina columns for analysis by GC/MS and GC/ECD. Aqueous phase samples were double extracted by liquid-liquid extraction with toluene. DeBDE was analysed by GC-ECD with a $10 \mathrm{~m}$ column to reduce compound degradation and all other PBDE congeners were analysed by GC/MS in NCl mode.

For the extraction of NPEO compounds, samples were initially centrifuged to separate the solid and aqueous phases. The solid phase extraction used a shaker method with double extraction using ethyl acetate followed by DCM. Extracts were 
cleaned over deactivated neutral alumina in preparation for LC/MS analysis. The aqueous phase samples were extracted by SPE using C18 cartridges. All compounds were detected by LC/MS-ESI, in positive mode for NPEO analysis and NP was detected in negative mode.

\section{Results}

\section{Acclimation time}

NPEO degradation was observed immediately and over a 49 day test period NP accumulated in mixed liquor suspended solids (MLSS), and proportionately more so in settled sludge. Figure 2 shows the total NP and NPEO concentrations detected. The effluent concentrations exhibited a steady increase with time irrespective of influent concentration as the more hydrophilic compounds not adsorbed to the MLSS were washed through the system.

PBDE degradation was not observed in the Husmann apparatus however, they accumulated in the solid phase. The total concentrations of each PBDE congener throughout the system remained constant. Degradation would have resulted in the accumulation of less brominated compounds and the reduction of BDE-209 or BDE183. With a constant influent concentration the concentrations in the MLSS and the settled sludge increased, this occurred proportionately more so in the settled sludge where more solids were available for binding in comparison to MLSS (Figure 3). PBDE test periods were shorter than for NPEO due to the adverse effects of PBDEs on the activated sludge bacteria. After a 25 day period the nature of the mixed liquor had changed, it had assumed a much deeper orange colour than was usually present, flocs were characterised under the microscope by being small and granular inter dispersed with fluffy filamentous aggregates. The bacterial composition also appeared to have changed and with this a concomitant change in surface properties and biochemical characteristics. Tests were stopped at this time as comparable data could not be obtained due to the potentially different bacterial surface properties. It is most likely that PBDE concentrations reached levels that were toxic to some bacterial species as a less diverse population appears to have developed when compared to unspiked Husmann MLSS (Figure 4). When PBDE influent was stopped and influent containing NPEOs continued, the diverse population returned within 14 days. As there was no PBDE degradation observed it 
is not possible that one species became dominant due to thriving on PBDEs and it is more likely one organism was resistant to toxicity. As exposure time to PBDEs increased the time to filter samples extended. With this increase in filter time there was a decrease in stirred sludge volume index (SSVI) indicating a reduction in settlability and predominance of small flocs which generally causes an increase in effluent turbidity which was also seen in the Husmann apparatus.

\section{Sludge Age}

At a higher $\varnothing_{\mathrm{c}}$ (7 days) the accumulation of NP and short chain NPEO compounds in the MLSS was more rapid than at a 3 day $\varnothing_{\mathrm{c}}$ (Figure 5$)$. The rate of production of shorter chain compounds in the system was also greater at 7 day $\varnothing_{\mathrm{c}}$ indicating more rapid losses of compounds with long chains. The biochemical oxygen demand (BOD) removal was greater at lower $\varnothing_{c}$ as expected but this does however result in poorer quality effluent ( 3 day $\varnothing_{c}$ BOD removal, $75 \% ; 7$ day $\varnothing_{c}$ BOD removal, $62 \%$ ). The higher F/M ratio at lower $\varnothing_{c}$ (3 day $\varnothing_{c}, F / M 321$ and 7 day $\varnothing_{c}, F / M 220$ ) is also an indication of poorer treatment efficiency and resulted in poorer quality effluent with higher suspended solids concentration and therefore greater concentration of hydrophobic compounds that would be bound to the suspended solids discharged. Higher $\varnothing_{c}$ results in less wash out of slow growing bacterial species facilitating degradation of more hydrophobic compounds that are generally more difficult to degrade and that may require a longer acclimation time.

For PBDEs, as demonstrated in figure 6, greater partitioning to the solid phase was observed at a $\varnothing_{\mathrm{c}}$ of 7 days than at 3 days due to the higher solids concentration. As well as the higher solids concentration, at a higher $\varnothing_{c}$ the mixed liquor is more hydrophobic and less negatively charged therefore facilitating increased PBDE adsorption. Competitive binding effects were also observed as partitioning to MLSS and sludge at $\varnothing_{c} 3$ days was less in the presence of NPEO compounds as some of the hydrophobic NPEO oligomers and NP competed for sorption sites on the solid phase.

\section{Shock Loadings}

During shock loadings the removal of compounds with greater than 5 ethoxy units remains constant demonstrating that sufficient amounts of enzymes required for this process are present. Biodegradation of more hydrophobic compounds, such as 
NPEOs with less than 5 ethoxy groups and NP, is controlled by the interface between the compound and water. The more hydrophobic a compound is the smaller the interface resulting in this being the likely rate limiting step under shock loading conditions. Bacteria were quickly adapted and despite continued elevated influent concentrations, the MLSS and settled sludge concentrations decreased 7 days after the initial shock loading and remained at a constant concentration and the BOD removal increased (Table 3).

For PBDEs, on day 12 the influent concentration was doubled for a period of 4 days. Figure 7 demonstrates that the additional PBDE load partitioned to the solid phase rather than being discharged via the effluent. However the increased partitioning to the mixed liquor remained high until the influent PBDE concentration reduced to the initial levels. Following this reduction in influent concentration, the PBDE concentrations in the solid phase reduced but remained higher than prior to the shock loading. As no degradation of PBDE occurred, these levels would remain elevated for one $\varnothing_{\mathrm{c}}$ until the biomass has been wasted from the system.

\section{Competition effects}

The concentrations of NPEO degradation products in MLSS also inoculated PBDE compounds was significantly less than during only NPEO inoculation, indicating that competitive binding or bio-inhibition reduced the availability of NPEO compounds for degradation due to PBDE compounds being more hydrophobic and occupying more of the available binding sites (Figure 5). The rates of partitioning for PBDE congeners were greater than NPEO oligomers therefore the binding sites available will be rapidly exhausted by PBDEs resulting in the NPEOs and NP being detected in higher concentrations in the effluent than with an absence of PBDEs.

\section{Discussion}

At low $\varnothing_{\mathrm{c}}$, the high mass flows of wasted sludge and the wash-out of slow growing specialised bacteria results in the major removal pathway being association with the solid phase, possibly as a result of high wastage resulting in high growth rates and rapid replenishment with new cells and relative abundance of unsaturated binding 
sites. Increasing the $\varnothing_{c}$ increases the MLSS concentration and reduces the amount of sludge wastage therefore results in a decrease in compound concentrations in the final effluent due to increased sorption and/or biodegradation by slower growing bacteria. Bacterial cells in the stationary phase of growth are more hydrophobic than those growing exponentially and sludge surfaces also become less negatively charged with a higher sludge age. Within the extra cellular polymeric substances (EPS) of the sludge floc the ratio of protein to carbohydrate increases with increasing $\varnothing_{c}$ corresponding with an increase in partitioning due to changing physico-chemical properties and increased solids concentration. Therefore, $\varnothing_{\mathrm{c}}$ becomes an influential treatment process variable for more hydrophobic compounds such as PBDEs, short chain NPEOs and NP, whose predominant removal mechanism is through association with biological flocs.

As the rate of compound removal of hydrophobic, lipophilic compounds generally correlates with the solids removal, if concentrations of effluent suspended solids are high it is probable that concentrations of other EDCs in effluent will also be elevated, as compounds with high log $\mathrm{K}_{\text {ow }}$ values will be associated with the nonsettlable solids. A low $\varnothing_{\mathrm{c}}$ leads to elevated effluent suspended solids and during the winter months when the temperature is lower the effluent suspended solids may be adversely affected with a concomitant impact on EDC removal. This agrees with other work where elevated PBDE concentrations were detected in effluent as well as sludge (North, 2004).

Compounds with a log $\mathrm{K}_{\mathrm{ow}}$ of less than 2.5 such as long chain NPEOs, exhibit minimal sorption potential and the major removal mechanism is degradation if compounds are susceptible. For compounds with log $\mathrm{K}_{\mathrm{ow}}$ values greater than 4, such as PBDEs, NP and short chain NPEOs, which are less susceptible to biodegradation, removal via association with solids is likely to be the major removal mechanism due to their high sorption potential and the higher rate of sorption as demonstrated in this and previous studies (Langford et al., 2005b). For this reason, biotransformations of susceptible compounds in the dissolved phase are governed by HRT and those in the solid phase are governed by $\varnothing_{c}$, which supports work reported elsewhere (Cowan et al., 1995). 
Competitive binding during wastewater treatment is feasible due to the variety of organic compounds generally found in sludge and this study indicates competitive binding is a possibility as more hydrophobic PBDEs were observed to adsorb to a greater extent than NPEOs despite being present in lower concentrations. Other work also supports the possibility of competition effects looking at pesticides and estrogens in sediment. Competitive binding may have an important effect on STW treatment efficiencies. Loadings from industrial sources potentially containing PBDEs may have a detrimental impact of the removal of hormones, pharmaceuticals or NPEOs for example as the available binding sites for these less hydrophobic compounds become exhausted due the partitioning of more hydrophobic industrial compounds such as PBDEs. Degradation of compounds more amenable to biodegradation will therefore be reduced as the initial important partitioning stage has been reduced.

The effects of competitive binding increase with compound hydrophobicity and could be useful in explaining the results for BDE-183 which is present in high concentrations in DE-79 but has shown results that do not correlate with other compounds in this study. An additional explanation for these results is that as PBDEs caused changes in the floc structure, they may prevent NPEOs from binding to the floc matrix as suggested elsewhere (Finlayson et al., 1998).

PBDE congeners exhibited toxic effects on bacteria and reduced population diversity within one sludge age of exposure. It is thought that many of the naturally occurring organobromine compounds provide protection for organisms by acting as antibacterial or antifungal agents, although it is only confirmed in a few cases (Gribble, 1999). PBDE metabolites are found in the Indonesian marine sponge, Dysidea herbacea, and may act as antibacterial agents (Gribble, 1999) therefore it is possible that PBDEs in activated sludge are also acting in the same way. An increase in filtration time for MLSS after exposure to PBDEs correlated $\left(r^{2}=0.91\right.$ 0.97) with a decrease in SSVI which was an indication of the dominance of small flocs and corresponded with an increase in effluent turbidity and a decrease in $\mathrm{pH}$. The $\mathrm{pH}$ reduction would result in a lower dissociation constant with a concomitant increase in repulsive electrostatic interactions. However, at neutral $\mathrm{pH}$, electrostatic interactions between positively charged groups on NPEOs $(-\mathrm{OH}$ or $-\mathrm{COOH})$ and 
the negatively charged microorganism surfaces are responsible for the majority of sorption (Liao et al., 2002). In the case of PBDEs which are not charged at neutral $\mathrm{pH}$ due to a lack of functional moieties, sorption is probably caused by non-specific sorption interactions (Ternes et al., 2004). As a consequence of reduced pH resulting from PBDE toxicity, the flocculating ability decreased and the large numbers of fine floc worsened effluent quality and also would impair dewatering ability (Liao et al., 2002). In studies looking at NP10EO a shift in bacterial population (Lozada et al., 2004; Barberio et al., 2001) was observed and a reduction in SSVI (Lozada et al., 2004). However, changing bacterial community composition does not necessarily mean a reduction of treatment efficiency. One study demonstrated no change in chemical oxygen demand (COD) removal despite marked changes in community structure (Kaewpipat and Grady, 2002).

A compounds affinity for the bacterial enzymes in activated sludge influences its degradation. The kinetics of biodegradation are dependent to a large extent on the adaptation of the bacterial population to the compound, either the selection of a specific bacterial species or the induction of enzymes within an existing species is necessary. However, in this study no acclimation time was required for NPEO degradation to occur, suggesting that the enzymes required were already present. This is not the case however for NP, which accumulated in the sludge and demonstrated no degradation suggesting the enzymes necessary for its degradation were not induced within the 47 day test period.

For synthetic organic compounds acclimation times increase at lower $\varnothing_{\mathrm{c}}$ and the extent of degradation is generally also less due to the low numbers of bacteria and concomitant low MLSS concentration. For compounds such as long chain NPEOs the enzymes required for breakdown are already present but in greater concentrations at a higher $\varnothing_{c}$ because of high bacterial numbers as a consequence of the high MLSS. In addition, an increasing $\varnothing_{\mathrm{c}}$ also results in greater bacterial and enzyme diversity. Therefore, as demonstrated in this work, degradation of long chain compounds is more rapid at a higher sludge age. However, at a higher $\varnothing_{\mathrm{c}} \mathrm{a}$ greater accumulation of shorter chain compounds was observed as a consequence of the higher degradation rates of compounds with greater than 7 ethoxy units. An exposure time of 47 days did not ensure induction of sufficient enzymes for 
degradation of the higher concentrations of shorter chain compounds and their rate of production exceeded their rate of removal as degradation becomes more difficult as the ethoxy chain shortens due to the influence of the phenolic ring.

At the low concentrations, compared to other carbon sources, at which NPEOs, NP and PBDEs occur in STW, biological transformations or degradation only occur if a primary substrate is available for growth, therefore it is possible that cometabolism occurs. Accumulation of metabolites which characterises cometabolism results from the failure of an enzyme due to either expression of strict substrate specificity or inhibition by toxic enzyme products. The $\varnothing_{\mathrm{c}}$ still remains a relevant parameter even if the compound is only degraded as a co-substrate because the bacterial growth rate and population diversity remains important for the degradation of the compound. It is also possible that mixed-substrate growth takes place for compounds such as NPEOs and the bacteria use the trace NPEO concentrations as a carbon and energy source and may mineralise it completely (Ternes et al., 2004).

In the presence of more hydrophobic compounds such as PBDEs, a reduction in NPEO partitioning was observed; the subsequent result of this would be a reduction in the amount of degradation. If the long chain compounds are left intact there will be an increase in the total nonylphenolic compounds discharged via the effluent, as the long chain compounds will have a preference for the aqueous phase rather than partitioning to the sludge. In STW competition effects are likely to occur more frequently with other compounds also competing for binding sites, which may further increase the concentrations of PBDE, NP and short chain NPEO congeners entering water courses. Shock loads to the system would also increase concentrations in the effluent. Increased loads of NPEO to the system resulted in elevated effluent and solid phase concentrations for 7 days after the increase while more enzymes were induced.

As NP and short chain ethoxylate compounds are toxic it is possible that feedback inhibition mechanisms occurred to prevent the formation of toxic concentrations of NP. When levels of NP reach a toxic concentration enzyme inhibition may prevent further degradation of longer chain compounds to prevent production of NP 
(Langford et al., 2005a). To investigate this hypothesis, increasing exposure times would have been required to determine whether further enzyme induction would enable biodegradation to proceed or whether NP concentrations were too high possibly resulting in feedback inhibition.

The removal of the long chain NPEOs and PBDEs from wastewater streams in efficient STW will generally be achieved. However, the problem arises due to the non-polar, hydrophobic nature of PBDEs, NP and short chain NPEOs and it would seem that the majority of these compounds would be removed from the aqueous phase by sorption to solids. This will likely result in accumulation of high concentrations of hydrophobic compounds in the sludge and have implications for sludge disposal routes. For high loaded systems the most important removal pathway from the aqueous phase is adsorption to sludge but when the HRT is lower than the time required for the adjustment of the adsorption equilibrium, the maximum adsorption may not be attained (Kruezinger et al., 2004).

The primary function of STWs is the removal of nitrogen, phosphorus and ammonia and the discharge of effluent with a low BOD and low suspended solids. Treatment processes have been designed to consider these requirements, and the removal for EDCs is a relatively new concept. The complex mixtures of EDCs and other xenobiotic compounds occurring in wastewater influent may be difficult to eliminate due to widely different physcio-chemical properties. The PBDE flame retardants and NPEO surfactants assessed in this research cover the wide range of properties that may be found. In each case, an increase in $\varnothing_{c}$ appears to be an important parameter and will also improve the removal of inorganic compounds. There is likely to be an optimum $\varnothing_{c}$ for STW operation (Clara et al., 2005), above which the benefits of EDC removal by increased degradation or partitioning will be outweighed by the increase in sludge production. A high sludge production resulting from an increased $\varnothing_{c}$ leads to the problem of the disposal of sludge, which is likely to be contaminated with hydrophobic EDCs and other compounds.

\section{Conclusions}


- Sludge age is important for biodegradation. Greater MLSS concentrations and perhaps greater species diversity at a higher sludge age enabled more rapid degradation of long chain NPEOs. However, an accumulation of short chain compounds and NP was observed as their rate of formation exceeded their rate of degradation at all sludge ages and particularly at a higher sludge age due to rapid long chain compound biodegradation.

- Bacteria adapt to NPEOs under conditions of shock loadings and degradation is observed within 7 days.

- No degradation of PBDEs was observed. Compounds are resistant to degradation if they fail to enter the bacterial cell because of an absence of suitable permeases or if their insolubility/adsorption renders them unavailable to microbial action or if there is no electron acceptor present.

- PBDE exhibited toxic effects on bacteria and reduced population diversity within one sludge retention time.

- Competition effects had an impact on partitioning and therefore also degradation. In the presence of PBDEs, less NPEO degradation was observed therefore less accumulation of short chain NPEOs and NP occurred. Less partitioning of PBDEs was also observed in the presence of NPEOs. The result of both would be an increase in hydrophobic endocrine disrupting compounds being discharged in effluent.

- More PBDE and NPEO removal was observed from influent at higher sludge age resulting in greater PBDE, NP and short chain NPEO compound accumulation in sludge. However, even at low sludge age accumulation of these compounds was observed. As the benzene rings were not degraded in either group of compounds at any sludge age, accumulation would be an inevitable consequence.

- From this research it is apparent that the principle environmental risk of PBDE contamination after wastewater treatment is via sludge disposal routes. Treatment of wastewater containing NPEO surfactants poses environmental risks via two routes, some NPEO compounds may pass through into receiving waters and degradation products such as NP, NP1EO and NP2EO will enter the environment via sludge disposal. 


\section{References}

Barberio, C., Pagliai, L., Cavalieri, D. and Fani, R. (2001). Biodiversity and horizontal gene transfer in culturable bacteria isolated from activated sludge enriched in nonylphenol ethoxylates. Res. Microbiol. 152, 105-112.

Battersby, N.S., Sherren, A.J., Bumpus, R.N., Eagle, R. and Molade, I.K. (2001)The fate of linear alcohol ethoxylates during activated sludge treatment. Chemosphere 45, 109-121.

Clara, M., Kreuzinger, N. Strenn, B., Gans, O. and Kroiss, H. (2005). The solids retention time - a suitable design parameter to evaluate the capacity of wastewater treatment plants to remove micropollutants. Water Res. 39, 97-106.

Cowen, C.E., Larsson, R.T., Feijtel, C.J. and Rapaport, R.A. (1995). An improved model for predicting the ftae of consumer product chemicals in wastewater treatment plants. Water Res. 27, 561-573.

Desbrow, C., Routledge, E.J. Brighty, G.C. Sumpter, J.P. and Waldock, M. (1998). Identification of estrogenic chemicals in STW effluent. 1. Chemical fractionation and inVirto biological screening. Environ. Sci. Technol. 32, 1549-1558.

Finlayson, J.C., Liao, B. Droppo, I.G. Leppard, G.G. and Liss, S.N. (1998). The relationship between the structure of activated sludge flocs and the sorption of hydrophobic pollutants. Water Sci. Technol. 37, 353-357.

Gao, J.P.,Maguhn, J., Spitzauer, P. and Kettrup, A. (1998). Sorption of pesticide sin the sediment of the Teufelsweiher pond (Southern Germany). 11. Competitve adsorption, desorption of aged residues and effect of dissolved organic carbon. Water Res. 32, 2089-2094.

Gribble, G.W. (1999). The diversity of naturally occurring organobromine compounds. Chem. Soc. Rev. 28, 335-346.

Gustafsson, K., Bjork, M., Burreau, S. and Gilek, M. (1999). Bioaccumulation kinetics of brominated flame retardants (polybrominated diphenyl ethers) in blue mussels (Mutilus edulis). Evniron. Toxicol. Chem. 18, 1218-1224.

Jacobsen, B.N., Nyholm, N., Pedersen, B.;., Poulsen, O. and Ostfeldt, P. (1993). Removal of organic micropollutants in lab activated sludge reactors under various operating conditions: sorption. Water Res. 27, 1505-1510.

Kaewpipat, K and Grady, C.P.L. (2002). Microbial population dynamics in laboratory scale activated sludge reactors. Water Sci, Technol. 46, 19-27. 
Kreuzinger, N., Clara, M., Strenn, B. and Kroiss, H. (2004). Relevance of the sludge age (SRT) as design criteria for wastewater treatment plants for the removal of endocrine disruptors and pharmaceuticals from wastewater. Water Sci. Technol. 50, 149-156.

Lai, K.M., Johnson, K.L., Scrimshaw, M.D. and Lester, J.N. (2000). Binding of waterborne steroid estrogens to solid phases in river and estuarine systems. Environ. Sci. Technol. 34, 3890-3894.

Langford, K.H. and Lester, J.N. (2002). Fate and behaviour of endocrine disruptors in wastewater treatment processes. In Endocrine Disruptors in Wastewater and Sludge Treatment Processes. Eds. Birkett, J.W. and Lester, J.N. CRC Press, Florida, USA.

Langford, K.H., Scrimshaw, M.D. and Lester, J.N. (2004). Analytical methods for the determination of alkylphenolic surfactants and polybrominated diohenyl ethers in wastewater and sewage sludges 11. Method development. Environ. Technol. 24, 975-985.

Langford, K.H. Scrimshaw, M.D. and Lester, J.N. (2005a). Degradation of alklyphenolic surfactants in activated sludge batch tests. Water Res. 39, 870-876. Langford, K.H. Scrimshaw, M.D. and Lester, J.N. (2005b). The partitioning of alkylphenolic surfactants and polybrominated diphenyl ether flame retardants in activated sludge batch tests. Chemosphere (In press).

Legler, J. and Brouwer, A. (2003). Are brominated flame retardants endocrine disruptors? Environ. Int. 29, 879-885.

Liao, B.Q., Allen, D.G., Leppard, G.G. and Liss, S.N. (2001). Surface properties of sludge and their role in bioflocculation and settleability. Water Res. 35, 339-350.

Lozada, M., Itria, R.F., Figueroa, L.A., Babay, P.A., Gettar, R.T., de Tullio, L.A. and Erijam, L. Bacterial community shifts in nonylphenol polyethoxylates-enriched activated sludge. Water Res. 38, 2077-2086.

Meakins, N.C., Bubb, J.M. and Lester, J.N. (1994). The fate and behaviour of organic micropollutants during wastewater treatment. Int. J. Environ. Poll. 4, 27-58. Meerts, I.A.T.M., Letcher, R.J., Hoving, S., Marsh, G., Bergman, A., Lemmen, J.G., van der Burg, B. and Brouwer, A. (2001). In vitro estrogenicity of polybrominated diphenyl ethers, hydroxylated PBDEs, and polybrominated bisphenol A compounds. Environ. Health Persp. 109, 399-407. 
Meerts, I. A. T. M., J. J. van Zanden, E. A. C. Luijks, I. van Leeuwen-Bol, G. Marsh, E. Jakobsson, A. Bergman and A. Brouwer (2000). Potent competitive interactions of some brominated flame retardants and related compounds with human transthyretin in vitro. Toxicol. Sci. 56, 95-104.

North, K.D. (2004). Tracking polybrominated diphenyl ether releases in a wastewater treatment plant effluent, Palo Alto, California. Environ. Sci. Technol. 38, 4484-4488.

Obeng, L.A., Lester, J.N. and Perry, R. (1981). Effect of mixed liquor suspended solids concentration on the biodegradation of nitrilotriacetic acid in the activated sludge process. Chemosphere 110, 1005-1009.

Rossin, A.C., Perry, R. and Lester, J.N. (1982). The removal of nitrilotriacetic acid and its effect on metal removal during biological sewage treatment 1. Adsorption and acclimation. Environ. Poll. 29, 271-302.

Routledge, E. J. and J. P. Sumpter (1996). Estrogenic activity of surfactants and some of their degradation products assessed using a recombinant yeast screen. Environ. Toxicol. Chem. 15, 241-248.

Scrimshaw, M.D. and Lester, J.N. (1997). Estimates of the inputs of polychlorinated biphenyls and organochlorine insecticides to the River Thames derived from the sediment record. Phil. Trans. Math. Phys.Eng. Sci. 355, 189-212.

Servos, M. R. (1999). Review of aquatic toxicity, estrogenic responses and bioaccumulation. Water Qual. Res. J. Can. 34, 123-177.

Stoveland, S. and Lester, J.N. (1980) A study of the factors which influence metal removal in the activated sludge process. Sci. Total Environ. 16, 37-54.

Szymanski, A., Wyrws, B., Swit, T., Jaroszynski, T. and Lukaszewski, Z. (2000). Biodegradatio of fatty acid alcohol ethoxylates in the continuous flow activated sludge test. Water Res. 34, 1401-4109.

Szymanski, A., Wyrws, B., Bubienm, E., Kurosz, T., Hreczuch, W., Zembrzuski, W and Lukaszewski, Z. (2002). Biodegradation of oxo-alcohol ethoxylates in the continuous flow activated sludge simulation test. Water Res. 36, 378-3386.

White, R., S. Jobling, S. A. Hoare, J. P. Sumpter and M. G. Parker (1994). Environmentally persistent alkylphenolic compounds are estrogenic. Endocrin. 135, 175-182. 
Table 1. Synthetic sewage medium

\begin{tabular}{lcc}
\hline \multicolumn{1}{c}{ Compound (VWR, UK) } & Mass in $10 \mathrm{~L}$ aspirator $(\mathrm{g})$ & $\begin{array}{c}\text { Influent concentration } \\
\left(\mathrm{g} \mathrm{l}^{-1} \mathrm{hr}^{-1}\right)\end{array}$ \\
\hline Bacterial peptone & 93.6 & 0.26 \\
Meat extract & 62.4 & 0.18 \\
Sodium chloride & 3.8 & 0.01 \\
Calcium chloride & 1.92 & 0.0055 \\
Magnesium sulphate & 0.6 & 0.0017 \\
hydrate & & 0.08 \\
Ammonium chloride & 28.8 & 0.0075 \\
Potassium dihydrogen & 2.6 & \\
orthophosphate & & \\
\hline
\end{tabular}


Table 2. Characteristics of Husmann influent and effluent

\begin{tabular}{|c|c|c|}
\hline Characteristic & Influent $\left(\mathrm{mg} \mathrm{l}^{-1}\right)$ & Effluent $\left(\mathrm{mg} \mathrm{l}^{-1}\right)$ \\
\hline & 350 & 46 \\
\hline COD & & \\
\hline BOD & 186 & 25 \\
\hline
\end{tabular}


Table 3. BOD removal as a percentage before and after NPEO shock loadings

\begin{tabular}{l|cccccccc}
\hline Test Day Number & 1 & 7 & 15 & 20 shock load & 22 & 24 & 27 & 31 \\
BOD removal $(\%)$ & 50 & 61 & 73 & 4 & 8 & 18 & 30 & 60 \\
\hline
\end{tabular}




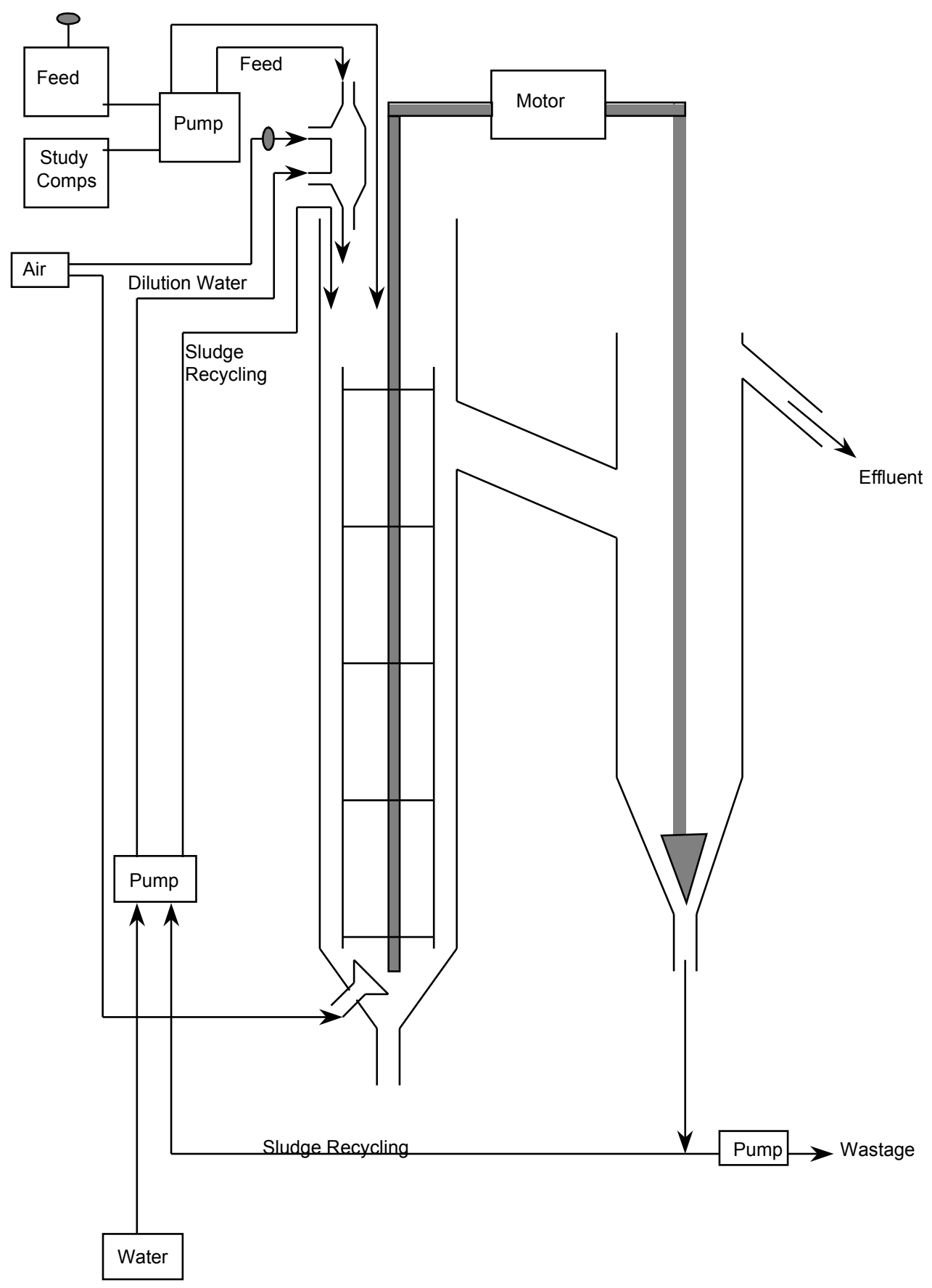

Figure 1 Schematic diagram of Husmann apparatus 


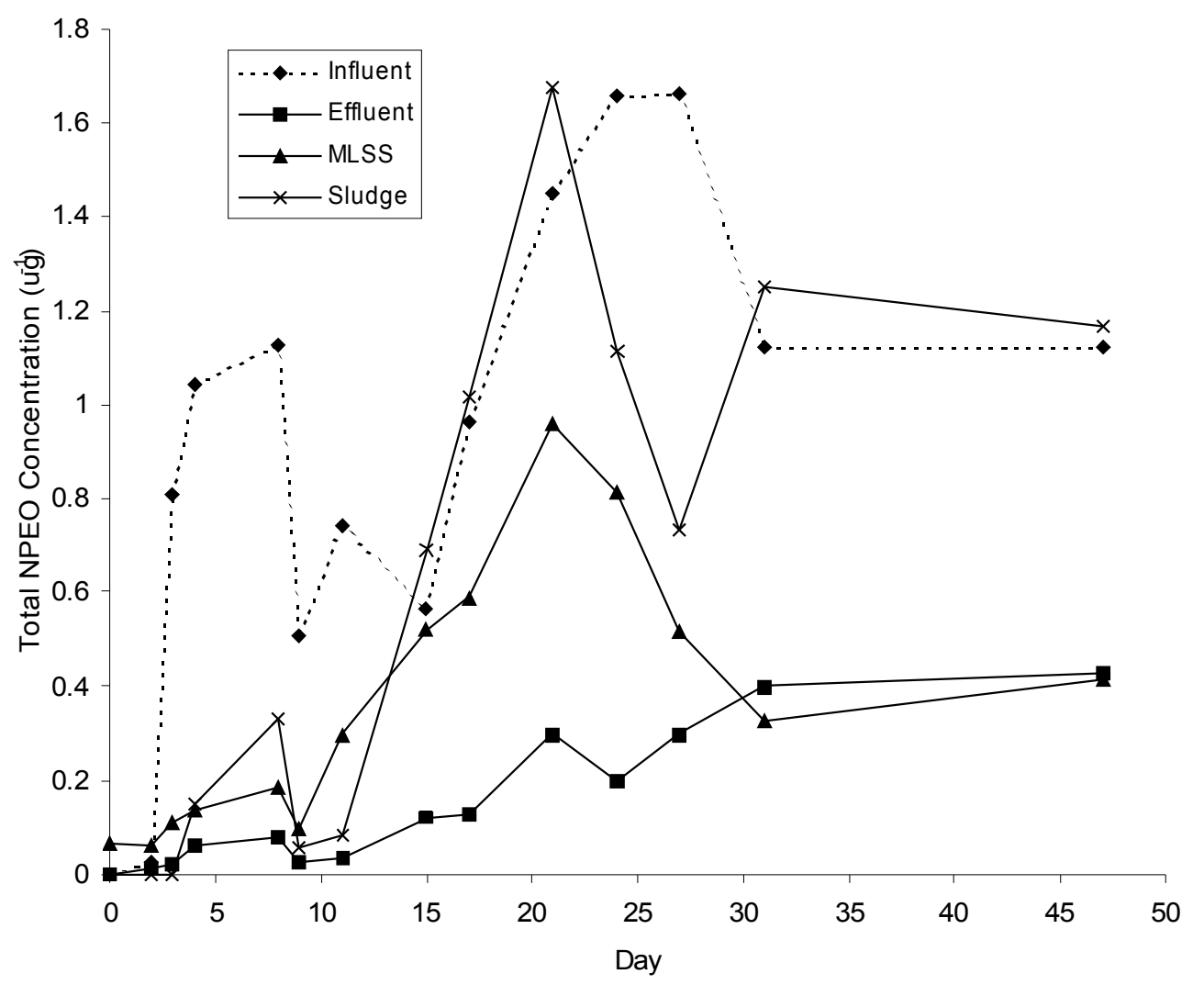

Figure 2. Total NP concentrations at a 5 day $\varnothing_{c}$ 

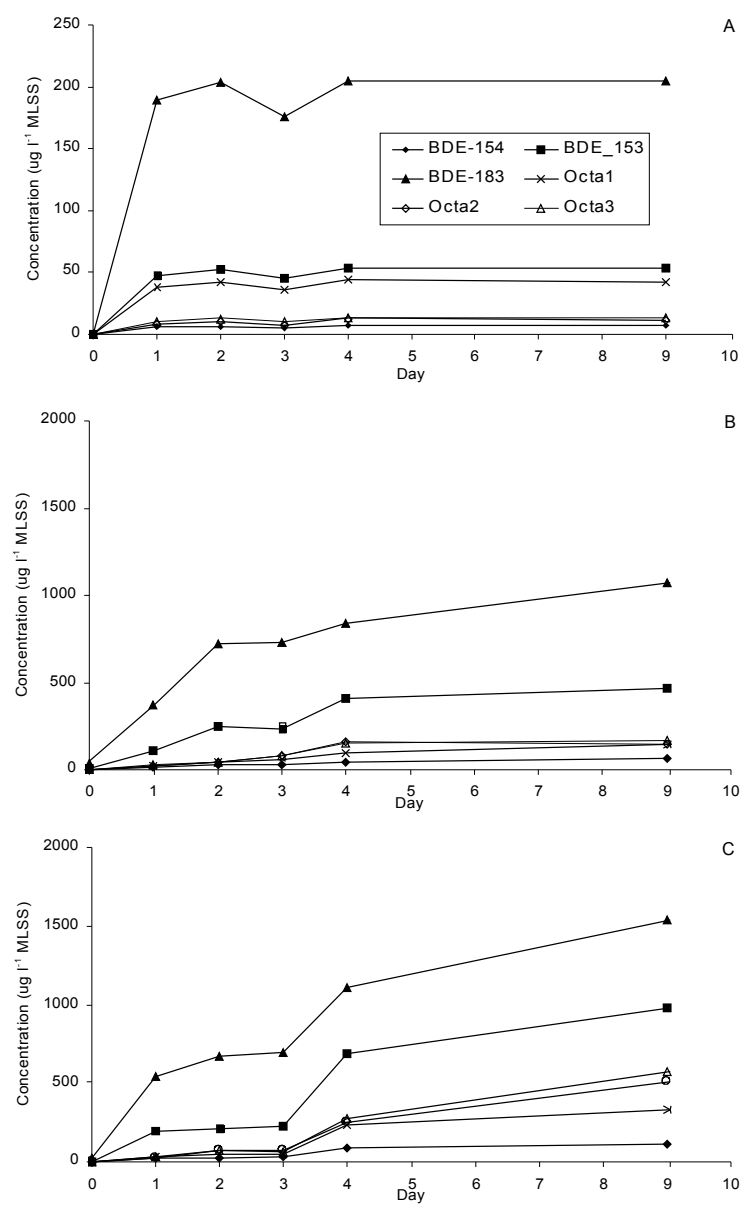

Figure 3. PBDE partitioning in Husmann apparatus with a 3 day $\varnothing_{\mathrm{c}}$. A. Influent B. MLSS C. Sludge 
A

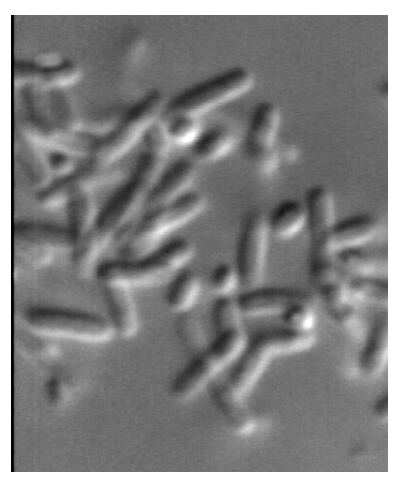

B

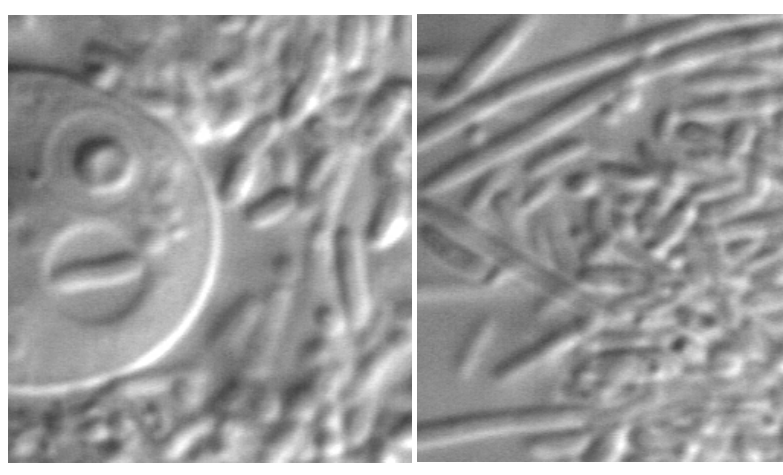

Figure 4. Husmann bacterial composition (x 1000 magnification) A. After 7 days PBDE exposure. B and C. Unspiked samples. 

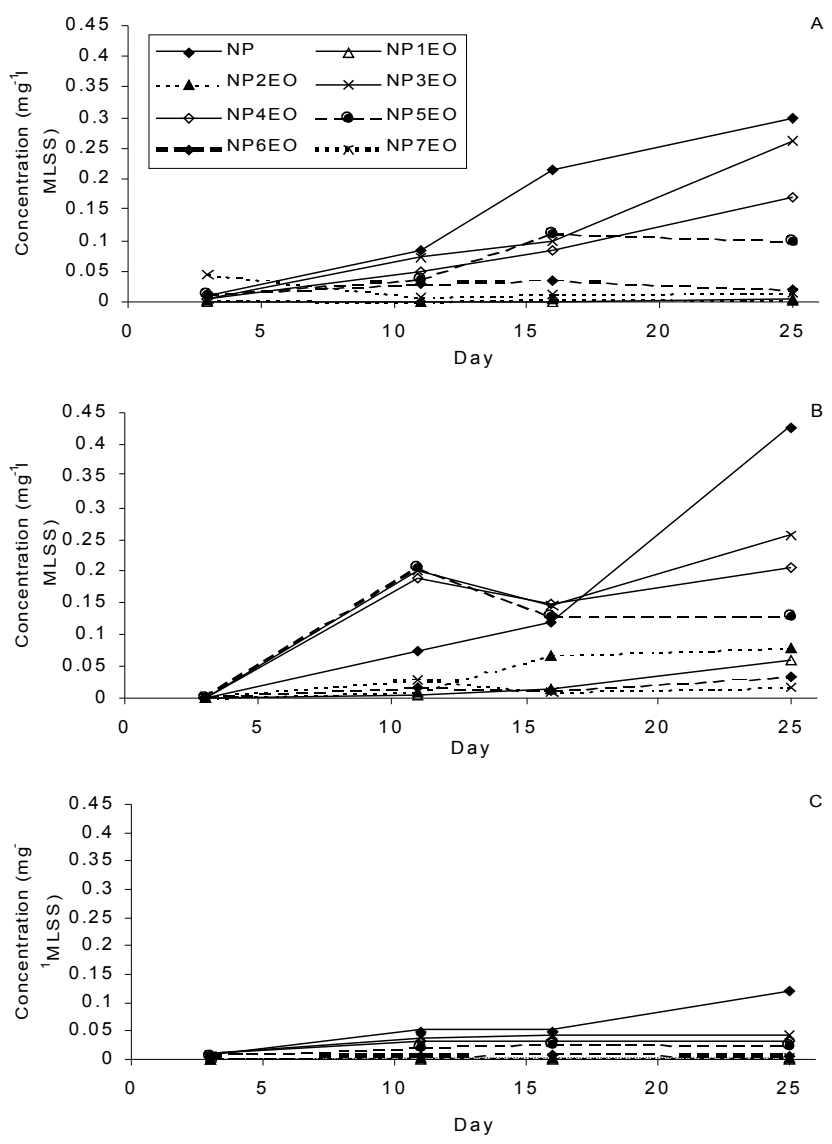

Figure 5. Degradation of some NPEO compounds in Igepal CO520 in Husmann apparatus aeration vessel. $A$ at $\varnothing_{\mathrm{c}} 3$ days, $B$ at $\varnothing_{\mathrm{c}} 7$ days and $C$ at $\varnothing_{\mathrm{c}} 3$ days in presence of PBDE compounds. 


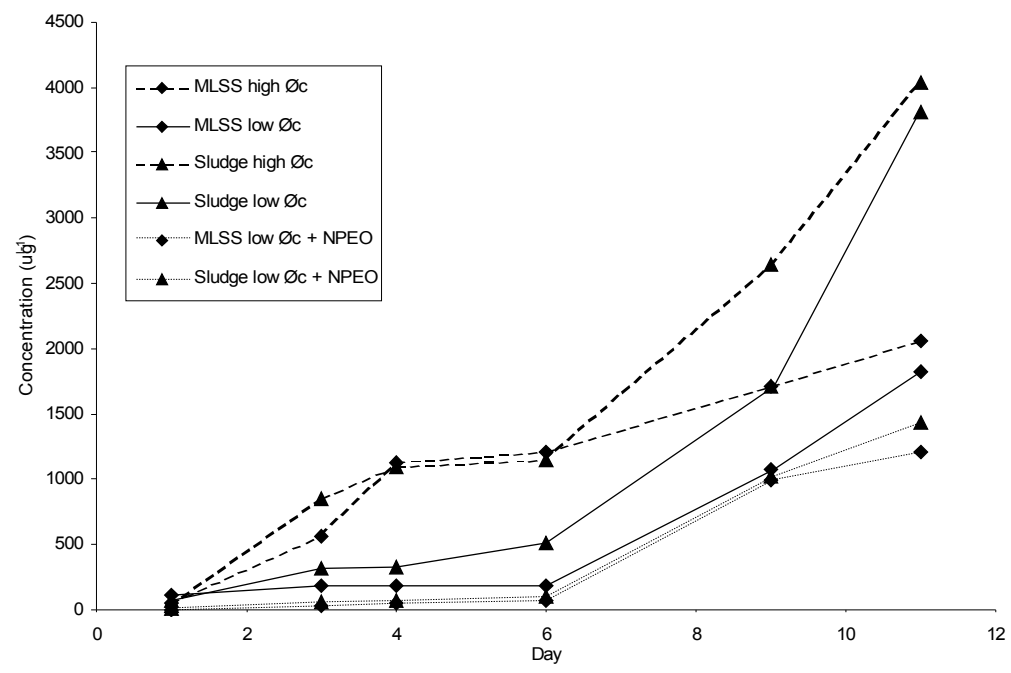

Figure 6. Total PBDE concentrations in the Husmann apparatus at different $\varnothing_{c}(3$ and 7 days) in the presence of NPEO and with PBDE as sole spiked compound 

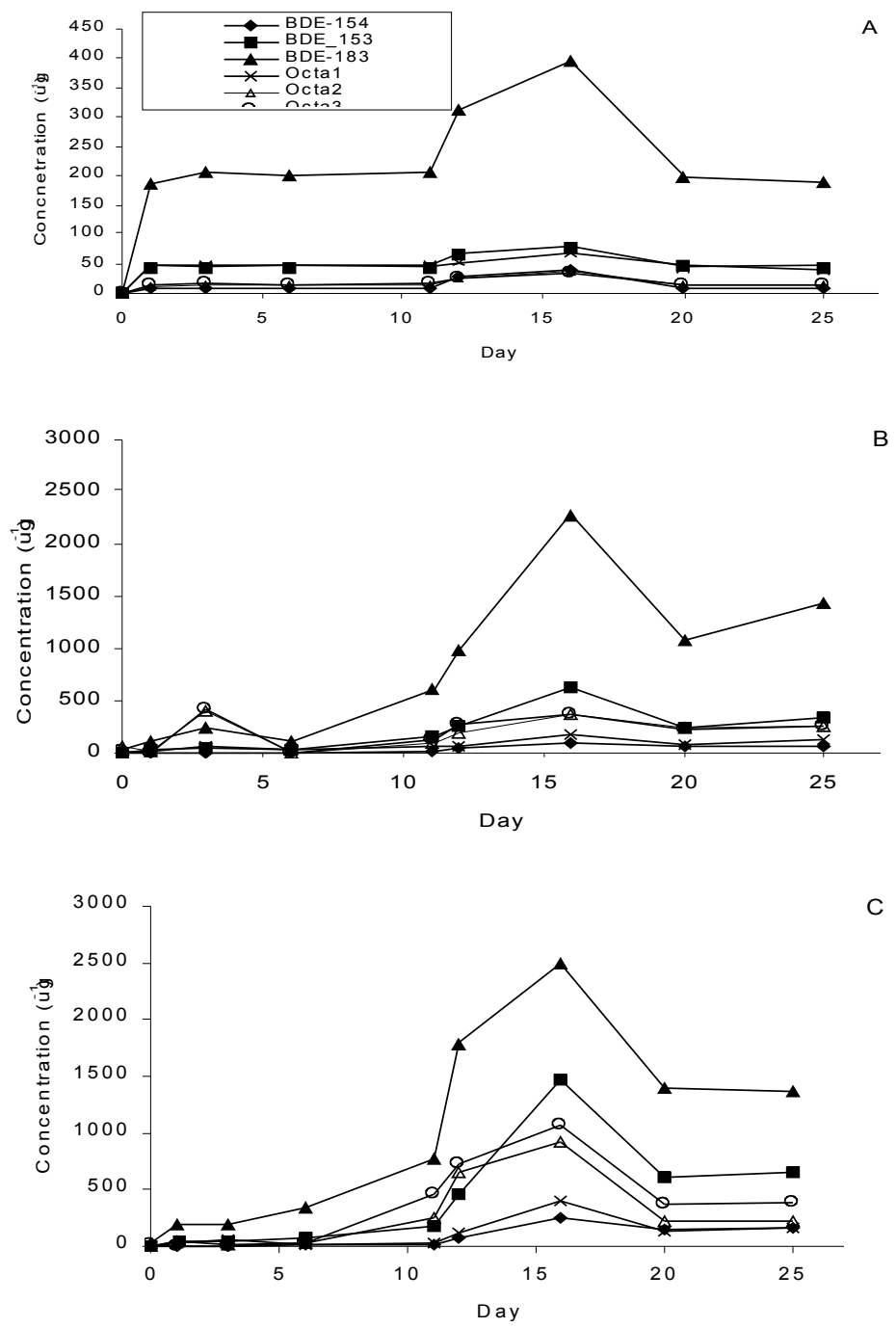

Figure 7. Partitioning of PBDEs in Husmann apparatus with a 5 day $\varnothing_{\mathrm{c}}$ with shock loading. A. Influent B. MLSS C. Sludge 


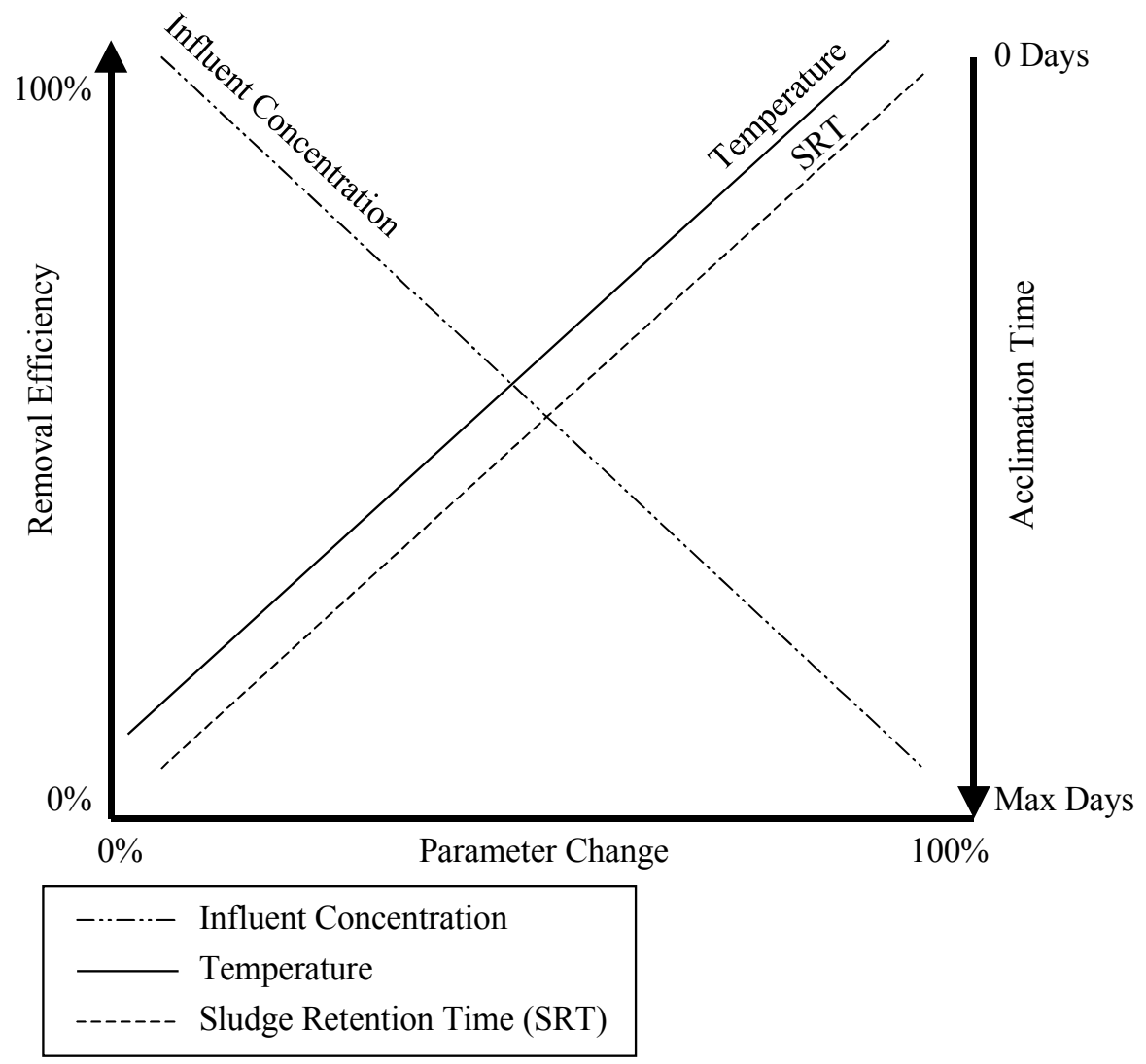

Figure 8. Effects of changing parameters on EDC removal efficiencies and acclimation time (adapted from Langford and Lester, 2002). 